\title{
THE INFLUENCE OF COVID-19 ON TEACHING-LEARNING ACTIVITIES: IS THERE NO COMING BACK WHEN THE PANDEMIC IS OVER?
}

\author{
A. Marinelli ${ }^{1}$, S. Bonetti ${ }^{2}$, D. Orecchia ${ }^{3}$ \\ ${ }^{1}$ Department of Chemistry, Materials, and Chemical Engineering "Giulio Natta", Politecnico di \\ Milano (ITALY) \\ ${ }^{2}$ Department of Mathematics, Politecnico di Milano (ITALY) \\ ${ }^{3}$ Department of Energy, Politecnico di Milano (ITALY)
}

\begin{abstract}
Posing unprecedented and unforeseen challenges to the educational system globally and across all levels, the SARS-CoV-2 pandemic worked as a powerful catalyst in the innovation of teaching practices.

In many cases, online and extended classrooms offered the chance to revise the course pedagogy to accommodate lockdown measures, quarantine, and social distancing. Meanwhile, the pandemic may foster better constructive alignment among the intended learning outcomes, teaching-learning activities (TLAs), and modified assessment strategies - or altogether innovating an existing course. Moreover, the employment of active TLAs may cope with the lack of motivation and involvement that sometimes labels online education.
\end{abstract}

This work sets in the Science, Technology, Engineering and Mathematics (STEM) higher education framework. The connection between innovative teaching before the pandemic and how COVID-19 affected traditional teaching methodologies is approached by discussing tools and their drivers.

Strengths and weaknesses are pointed out, including the TLAs and examples of relevant pedagogical frameworks tools are involved in or based on, respectively. A novel approach to discuss the adoption of tools along a four-axis domain (space, time, user activity, and interaction) is presented.

Finally, implications in a short-time horizon scenario characterized by extended classrooms and the changes that could be irreversible in the long run are addressed.

Keywords: Covid-19, teaching tools, teaching-learning activities, innovative teaching, digital technology.

\section{INTRODUCTION}

Before the great changes and disruptions brought forth by the COVID-19 pandemic, teaching in higher education Science, Technology, Engineering and Mathematics (STEM) disciplines was still predominantly traditional in nature. The teacher speaker is the typical figure to be found. Aiming at covering as much content as possible in the available time, the teacher speaker usually leaves the bulk of the work - i.e. learning, organizing, applying, and solving problems - to the students' activity. Notwithstanding that applying the knowledge and solving new problems is of greatest importance in the STEM disciplines. Granted, tutorials and occasional laboratories are often part of the activities but are still not enough to ensure a completely satisfactory alignment with the intended learning outcomes (ILOs) that most professors desire for their students - those related to the highest levels of Bloom's revised taxonomy [1] (Fig. 1).

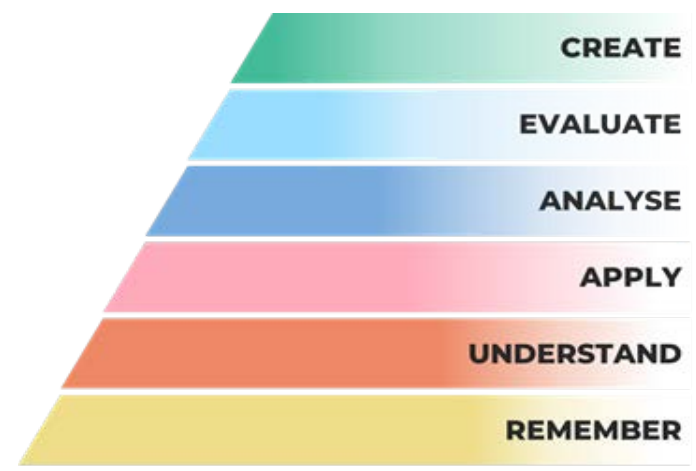

Figure 1. Revised Bloom's Taxonomy. 
Traditional teaching methods work good enough for the brightest students, who naturally engage by themselves in these higher-level activities [2]. However, if poorly engaged, the majority of students tend to develop a surface approach to learning.

Innovative teaching interventions work and are desirable, as widely described in the literature [3], [4]. One of the main overall conclusions from Hattie [4] is - indeed - that a wide range of actions can promote academic achievements ${ }^{1}$. In recent years, their adoption has risen, also thanks to institutional policies: at Politecnico di Milano, for instance, many courses started to include an innovative teaching activity, mainly through the flipped classroom approach. Still, their adoption is not widespread yet. Moreover, the inclusion of innovative teaching elements in an existing course requires a check for coherent alignment between ILOs, teaching-learning activities (TLAs) and assessment tasks (ATs) strategies in the course pedagogy - which is mandatory for teaching innovation.

In this context, the forced shift to online teaching due to the new SARS-CoV-2 pandemic has the potential to act as a catalyst for the diffusion of innovative teaching practices. Indeed, there is much to be learned by the experience, and some changes may be irreversible.

This work inspects how the pandemics have changed the teaching-learning practices with particular attention to the online tools that supported the switch to remote classes.

Concerning the tools, a four-dimensional classification is here presented: the different typologies of tools are classified according to their features related to attendance/space, time, user activity, and interaction. Lastly, the use of online tools is discussed in the short- and medium-term, with a particular focus on the framework of extended classrooms.

\section{TEACHING DURING THE COVID-19 PANDEMIC}

In March 2020, countries all over the world imposed lockdown measures as the new Sars-CoV-2 virus spread. This posed an unprecedented challenge to the education institutions: rearrange the in-presence courses to an online modality almost overnight. Granted, the emergency and its stringent time constraints did not allow a focus on online pedagogy, which is the main reason why "emergency remote teaching" (ERT) differs from "online learning" (OL) [5]-[7].

The former refers to a temporary online shift due to external circumstances, to revert as soon as the situation improves; the latter, instead, is a course entirely planned and designed for remote delivery. Hence, unsurprisingly, OL is not inherently worse than in presence learning [5], while ERT may often be. Part of the reason is due to the specific expertise required for online learning, comprising not only content knowledge and pedagogical knowledge but also technological knowledge - with all the interplays among the three as in the TPACK framework [8]. Indeed, among the many ERT experiences reported in the literature, it is clearly stated that instructors' previous expertise in OL is most beneficial [9], [10]. Moreover, teachers familiar with teaching methods promoting involvement and interaction such as group activities and projects - achieved better results. This highlights the importance of engagement, an issue in ERT (and OL) that is likely to occur compared to a physical classroom.

Further issues were encountered in ERT [11]: the availability of a stable internet connection along with proper equipment is not to be taken for granted, and the same is true for a proper quiet place to follow the lectures. It is important to note that providing recordings or allowing to carry out the required activities asynchronously can effectively mitigate this issue.

In light of the characteristics and issues of remote teaching and learning, proper exploitation of online tools for the teaching-learning process is fundamental. Each tool can be better suited for a specific TLA, potentially suggesting or enabling new ones depending on its usage. This - along with increased dexterity in their use - may influence the instructors' way of teaching even after the pandemic, in the direction of innovative teaching practices supported by online tools. According to Koheler \& Mishra [8], online tools should not be used "for the sake of it", but to promote the students' learning and understanding, with a specific pedagogical aim.

\footnotetext{
${ }^{1}$ Most of the meta-analyses employed in Hattie's work do not refer to universities. However, as the author himself argues [17], there is enough data to support the conclusion that what works in K-12 also works in universities - where applicable.
} 


\section{ONLINE TOOLS AND THEIR FEATURES}

Literature abounds of case studies and tools used in ERT due to the COVID-19 pandemic, with some software having roots in previous literature.

The purpose of this paragraph is to relate and discuss macro-categories of online tools to the situations in which their use is of help while teaching a course.

Table 1 collects only some of the existing tools, altogether with some associated TLAs and ATs. Only the main features are displayed, albeit tools may be used for multiple TLAs or ATs, e.g. Cisco WebEx as a videoconferencing or polling tool.

The main typologies of tools were identified following a bottom-up process, i.e. from the specific tool to the general category depending on its features. Tools were retrieved from both the literature and the authors' previous knowledge.

Table 1. Clustering of the main typologies of tools and their related TLAs and ATs.

\begin{tabular}{|c|c|c|c|c|}
\hline TYPE & DESCRIPTION & TOOLS & TLAs & ATs \\
\hline Videoconferencing & $\begin{array}{l}\text { Tools which stream audio, } \\
\text { video, and/or screen. They aim } \\
\text { at emulating the classroom }\end{array}$ & $\begin{array}{l}\text { Microsoft Teams, Skype, } \\
\text { Zoom, Cisco WebEx, } \\
\text { Blackboard Collaborate Ultra, } \\
\text { YouTube }\end{array}$ & $\begin{array}{l}\text { Lectures, } \\
\text { Guest speakers }\end{array}$ & Oral exams, Proctoring \\
\hline Presentations & $\begin{array}{l}\text { Tools that create lectures or } \\
\text { generally content to be shared } \\
\text { with the class }\end{array}$ & $\begin{array}{l}\text { Microsoft Powerpoint, Google } \\
\text { Presentations, Canva, } \\
\text { Wooclap, Zeetings }\end{array}$ & Lectures (interactive) & \\
\hline Quiz/Polling & $\begin{array}{l}\text { Tools that collect } \\
\text { feedback/answers from the } \\
\text { learner, improve interaction } \\
\text { and discussion, and/or allow } \\
\text { assessment }\end{array}$ & $\begin{array}{l}\text { Kahoot!, Socrative, Microsoft } \\
\text { Forms, Google Forms, } \\
\text { Wooclap, Zeetings }\end{array}$ & $\begin{array}{l}\text { Brainstorming, Polling, } \\
\text { Quiz, Tutorials/Labs }\end{array}$ & $\begin{array}{l}\text { Quiz (open/closed } \\
\text { Q\&A) }\end{array}$ \\
\hline MOOC repository & $\begin{array}{l}\text { Platforms that gather entire } \\
\text { courses or modules. }\end{array}$ & $\begin{array}{l}\text { Coursera, Udemy, MIT } \\
\text { OpenCourseWare, Polimi } \\
\text { Open Knowledge }\end{array}$ & $\begin{array}{l}\text { Lectures (modules), } \\
\text { Flipped Classroom }\end{array}$ & $\begin{array}{l}\text { Partial grades } \\
\text { (modules), Continuous } \\
\text { assessment }\end{array}$ \\
\hline $\begin{array}{l}\text { Learning Management } \\
\text { System (LMS) }\end{array}$ & $\begin{array}{l}\text { Platforms that collect the } \\
\text { material of a course and allow } \\
\text { teachers to share it with the } \\
\text { learners. Usually, they include } \\
\text { communication systems e.g. } \\
\text { forums. }\end{array}$ & $\begin{array}{l}\text { Blackboard Learn, BeeP, } \\
\text { Perusall, Kaltura }\end{array}$ & $\begin{array}{l}\text { Collaborative learning, } \\
\text { Flipped Classroom }\end{array}$ & \\
\hline Forum & $\begin{array}{l}\text { Tools that allow } \\
\text { communication among the } \\
\text { actors (usually teacher and } \\
\text { students) }\end{array}$ & Padlet, Piazza & $\begin{array}{l}\text { Q\&A sessions, } \\
\text { Collaborative learning }\end{array}$ & \\
\hline $\begin{array}{l}\text { Collaborative } \\
\text { Environment }\end{array}$ & $\begin{array}{l}\text { Platforms meant for teamwork. } \\
\text { They involve virtual } \\
\text { environments in which the } \\
\text { users add, organise, and } \\
\text { generate content }\end{array}$ & Miro, Mural & $\begin{array}{l}\text { Concept maps, } \\
\text { brainstorming, group } \\
\text { work }\end{array}$ & \\
\hline
\end{tabular}


Table 2. A 4-dimensional classification of the different typologies of tools.

\begin{tabular}{|c|c|c|c|c|c|c|c|c|c|}
\hline \multirow[b]{2}{*}{ TYPE } & \multicolumn{2}{|c|}{ SPACE } & \multicolumn{2}{|c|}{ TIME } & \multicolumn{2}{|c|}{$\begin{array}{c}\text { USER } \\
\text { ACTIVITY }\end{array}$} & \multicolumn{3}{|c|}{ COMMUNICATION } \\
\hline & $\begin{array}{l}\stackrel{\mathscr{E}}{\bar{E}} \\
\text { o }\end{array}$ & 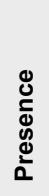 & 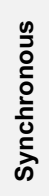 & $\begin{array}{l}\frac{0}{3} \\
0 \\
\frac{0}{0} \\
\frac{2}{0} \\
\frac{0}{0} \\
\frac{0}{2}\end{array}$ & 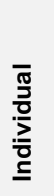 & $\begin{array}{l}\stackrel{0}{0} \\
\text { 인 }\end{array}$ & 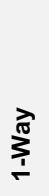 & 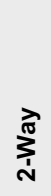 & $\frac{\sum_{1}^{\frac{\pi}{1}}}{\frac{1}{5}}$ \\
\hline Videoconferencing & $\checkmark$ & $\checkmark$ & $\checkmark$ & & $\checkmark$ & $\checkmark$ & & $\checkmark$ & $\checkmark$ \\
\hline Presentations & $\checkmark$ & $\checkmark$ & $\checkmark$ & $\checkmark$ & $\checkmark$ & & $\checkmark$ & $\checkmark$ & \\
\hline Polling & $\checkmark$ & $\checkmark$ & $\checkmark$ & & $\checkmark$ & $\checkmark$ & $\checkmark$ & $\checkmark$ & \\
\hline MOOC repository & $\checkmark$ & & & $\checkmark$ & $\checkmark$ & & $\checkmark$ & & \\
\hline LMS & $\checkmark$ & & & $\checkmark$ & $\checkmark$ & $\checkmark$ & & & $\checkmark$ \\
\hline Forum & $\checkmark$ & & $\checkmark$ & $\checkmark$ & $\checkmark$ & & & & $\checkmark$ \\
\hline $\begin{array}{l}\text { Collaborative } \\
\text { Spaces }\end{array}$ & $\checkmark$ & & $\checkmark$ & $\checkmark$ & & $\checkmark$ & & & $\checkmark$ \\
\hline Proctoring & $\checkmark$ & & $\checkmark$ & & $\checkmark$ & & $\checkmark$ & & \\
\hline
\end{tabular}

Table 2 highlights the appropriateness of a tool according to four main drivers (i.e. axis):

- Space: where are the TLAs and ATs meant to take place?

- Time: are the different actors expected to perform, carry, or complete activities and tasks simultaneously?

- User activity: are the activities designed to be individual or collaborative?

- Communication: is the information intended to be shared unidirectionally, bidirectionally or multidirectionally?

Hereafter, a brief description of the previous drivers is presented.

\subsection{Space}

The environment is essential for the teaching-learning experience. It is composed of a physical or virtual place and its furnishing, some actors, and actions that could be performed inside it [12]. This implies the interaction with the environment and with the people inside it. Therefore, the location and its configuration may allow or impede sociality in the learning experience.

Online tools may empower the possibilities given in the specific environment, e.g. allowing for remote attendance in extended classrooms, proctoring summative assessment for online classes, or providing flexible digital collaborative environments for group works.

Flexibility is key to online tools. Although natively digital, not all tools are intended to be used exclusively in online classes. Therefore, dual-use platforms show to be more flexible than others in terms of use. But flexibility can be found - among others - in accessibility, customisation, and adaptivity to the situation.

Unsurprisingly, online environments can apply all the considered typologies, while only a few (videoconferencing, presentation, and polling) seem that could be easily integrated into in-presence 
activities. This is not an issue in the case of OL, but for ERT the professor should carefully consider the effort put into learning the tool compared to its lifetime [13].

In the framework of extended classrooms, it is essential to rely on videoconferencing tools to incite synchronous interaction among in-presence and remotely-connected students, reducing barriers. Using these tools alone is often not enough: ambient microphones and cameras in the physical classroom may be required.

Moreover, in teaching methodologies involving experience as a milestone such as Kolb's Cycle, the environment may be crucial. Indeed, tangible laboratory experiences are essential factors in STEM education.

\subsection{Time}

Time management is pivotal for ERT and OL. The teacher has to choose synchronous and asynchronous TLAs and, according to them, suitable tools. In his work, Mutawa [14] compares different features of synchronous distance learning (SDL) and asynchronous distance learning (ADL) from both students' and teachers' perspective.

The main difference between ADL and SDL stands in immediate interaction with the teacher and other students, which is considerably higher in SDL. Asynchronous TLAs, on the contrary, are more flexible in terms of schedule and require less powerful technological systems; these aspects make them particularly suitable for student-workers and allow them to overcome digital and infrastructural divides. It is important to notice that many synchronous tools can provide material (e.g. lesson recordings) to students who cannot follow the lesson synchronously, being however less effective than synchronous TLAs.

According to preliminary findings [15], students attending synchronous classes obtain better results.

Synchronous and asynchronous TLAs can alternate into the same pedagogical framework. Indeed, in flipped classrooms, students can access the materials in MOOC repositories or LMS asynchronously. Later, using videoconferencing tools or in presence, they can discuss synchronously within the class.

At last, considering extended classrooms, teachers should reflect on the use of synchronous tools to achieve a simultaneous attendance of in-presence and remotely-connected students.

\subsection{User activity}

Interaction among students and teachers is essential in the learning process [16]. One of the main issues in ERT is the lack of the social aspect in TLAs, both among students and with the teacher, accentuated by the fact that many online tools used for teaching are meant to be used individually.

As visible in Table 2, Collaborative Environments are the only ones explicitly conceived to allow students to work and think together.

Nevertheless, software evolution integrated collaborative features in online tools. For instance, videoconferencing tools introduced breakout rooms, where students can work together aside from the lessons. However, the functionalities are still the same as in the principal room, i.e. chatting and video/audio sharing.

Teachers may also design TLAs requiring collaboration among students, exploiting software mainly intended for individual use. As an example, the teacher can propose a quiz to the classroom to be answered as the outcome of small group activities.

It should be noted that the use of synchronous collaborative tools in extended classrooms is not immediate because it depends on several factors e.g. number of students, in-presence and online participants, etc. On the contrary, the use of individual tools is easier to be integrated into such a context.

\subsection{Communication}

As already reported, learning is social [16]. Therefore, communication - whether written, verbal, or nonverbal - is essential. The richness and quality of information help the students in their learning process. On the other hand, the continuous collection of feedback may provide the teacher precious data to improve the course. 
Being the above-mentioned richness and quality strictly linked to the features of the tools - e.g. nonverbal information shared using a camera in a videoconferencing tool or verbal information provided filling a questionnaire - in this context the focus is on the direction of this exchange. Communication is here defined as (see also Fig. 2):

- One-Way $(1 \mathrm{~W})$, when it is carried by the tool only from one actor to another one, i.e. teacher-tostudent or student-to-teacher;

- Two-Way $(2 \mathrm{~W})$, when the second actor can provide further information back, i.e. from the student to the teacher and vice versa simultaneously;

- Multi-Way (MW), when there is maximum freedom in sharing information, i.e. student-student and student-professor, in both ways.
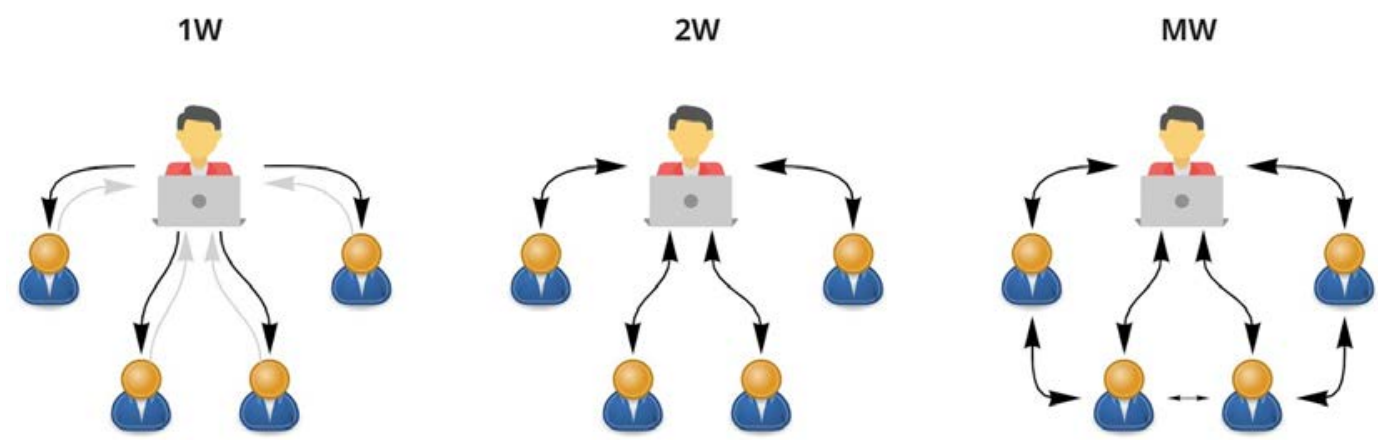

Figure 2. Visualisation of the different typologies of communication inside a class.

As visible in Table 2, there is a good repartition of tools in the three categories. Proctoring systems are intended to monitor the students during exams, thus are not $2 \mathrm{~W}$ or MW (though Al may provide feedback to the user). Same for MOOC repositories, meant to provide learners with information through video lessons and assessing it with exercises, questions, or quizzes.

Interestingly, collaborative spaces are powerful tools. They are developed to create, keep, and share (multimedia) information among different stakeholders. On the other hand, Forums and LMS can provide MW communication related to exchanging data, posing questions, discussing, etc.

Polling has been set to a $1 \mathrm{~W}$ level because results are generally not returned publicly. Regarding this topic, tools like Socrative, Kahoot!, Wooclap, and Zeetings stand out because they are developed for interactive lessons. These are $2 \mathrm{~W}$ tools, since users can create presentations, poll attendees, and share/comment the results live - yet having reports to be analysed after the seminar/lecture.

\section{DISCUSSION}

As already stated, COVID-19 acted as a catalyst in education, like it did in many other fields such as smartworking and remote collaboration. It primarily changed the perspective on online working: from a loss of efficiency to a real opportunity for both education and businesses. Indeed, today people are more used to online tools and more familiar with the integration of online activities into their daily work. Specifically, over the last year teachers enriched their digital skills and got used to online teaching; this is crucial, as the experience of educators in $\mathrm{OL}$ is a fundamental aspect in the success of remote learning [9].

On the other hand, even tools underwent substantial changes. This is particularly true for tools designed for smart-working. Indeed, the systems, platforms, and software - taking advantage of the massive "newcomers", i.e. thousands of courses redirected online - integrated educational features to apply to different contexts.

It is then reasonable to think that the experience brought by ERT will be exploited at least in a shortmedium timeframe.

Of course, tools must be picked carefully. They should enhance the constructive alignment of the program, though someone could use software simply to reduce the effort associated with teaching. Online tools should suit the TLAs and ATs that are most beneficial to the course ILOs. Regarding this topic, a work [13] reports some generic - yet essential — questions to help the selection process. 
In the learning context, online tools may be of great help in promoting innovative and active TLAs. For instance, MOOC repositories may play an important role in implementing the flipped classroom methodology; meanwhile, tools like Wooclap or collaborative environments as Miro could be beneficial for promoting collaborative and social TLAs. Consequently, it may become a step towards less traditional and frontal courses that are not typical of STEM courses.

Due to the persistence of the pandemic, remote teaching may be prolonged. We suggest extended classrooms as the best candidates for their flexibility in terms of location - which is beneficial to e.g. fragile people or actors living abroad - as well as in case of unfortunate circumstances such as quarantine and/or new lockdowns.

ERT and OL gave all the teachers the chance to reflect on the creation of a portal to the physical classroom, allowing people to follow synchronous and in-presence TLAs and ATs. A fundamental role will be covered by all the tools that allow synchronous attendance to remote students, like videoconferencing and presentation tools, and the ones that promote the interaction among remote and in-presence students, like the polling ones and the collaborative spaces.

Nevertheless, it is important to highlight three possible issues of online learning.

First of all, it is important - mainly for students - to have the chance to go back to in-presence lessons and to attend in-presence class whenever they can. There are many aspects for which an in-presence class is beneficial for a student: non-verbal communication is essential in teaching, it reduces mental health issues, and enhances sociality for young people - before the lesson, during breaks, or after. This last side refers to the importance of a non-virtual relationship. Indeed, meeting other people and ideas helps to develop a social conscience while enhancing the learning experience. As already stated, the relationship among the actors affects the quality of outcomes achieved through the learning process.

Secondly, the extended classroom may not be ideal for some TLAs that are peculiar of STEM education. It is the case of laboratory experiences that may involve expensive or voluminous equipment/materials, or cannot be replicated at home for safety reasons - e.g. activities that are to be carried in a chemical or biological laboratory.

Lastly, institutions must support the use of online tools: to make them available for in-presence students, institutions must provide adequate infrastructures, e.g. robust internet connections and power outlets in every classroom, as well as software licenses for both the teacher and the learner.

The short-term scenario of extended classrooms also poses issues related to ATs, since the instructor must select strategies that work well for both in-presence and remote students. The focus is here on the kind of knowledge to be assessed: declarative or functional. The (individual or group) oral discussion seems to be the ideal choice but may be excessively time-consuming for large classes. Group projects may promote cooperation and assess higher levels of Bloom's revised taxonomy, leaving further individual assessment to different ATs such as Artificial Intelligence-assisted multiple-choice quizzes for declarative knowledge or minute papers for functioning knowledge. Open-book exams could also be an appealing alternative for STEM disciplines, since they well fit relevant pedagogical frameworks like problem-based learning. Such ATs can build a climate of mutual trust between teacher and learners, that can instead be put in jeopardy when too strict invigilated exams are adopted - especially with online proctoring. Indeed, the lack of trust leads to a surface approach to learning, focusing on exercising only the lower levels of the revised Bloom's pyramid [2]. At the same time, assessment concerning verbs as "analyse", "create", or "evaluate" does not require an invigilated approach, leading to increased trust and thus a deeper approach to learning.

Nevertheless, online tools can be valuable in assessment too, both formative (e.g. through quizzes) and summative, automating the correction process - particularly useful for large classes.

\section{CONCLUSIONS}

The COVID-19 pandemic greatly affected the education environment and practices. Among the consequences, the one with the longest reaching effects may be the shift towards online learning and open knowledge. Indeed, ERT allowed the creation of enormous amounts of digitalised educational material ready to contribute to online courses or populate open knowledge platforms.

Moreover, this experience highlighted both the advantages and shortcomings of online education, paving the way to exploit the former while mitigating the latter. An example is videoconferencing, 
allowing delocalised guest speakers to share their expertise - in the general framework of technology bridging people. The same is true for international students, who could follow courses remotely.

Bridging technologies may increase networking and collaborations among different universities and countries. The extended classroom framework could be an interesting possibility in this regard, combining the advantages of in-presence and online learning. Consequently, the perdurance of extended classrooms even after the pandemic should be unsurprising.

Although someone would like to get rid of changes catalysed by the pandemic to get back to in-presence teaching, we suggest that it is more beneficial to take the best out of this ERT experience to shape the future of education. Besides, as with all disruptive changes, it may be impossible to go back to how things were before.

\section{REFERENCES}

[1] L. W. Anderson et al., Eds., A taxonomy for Teaching, Learning, and Assessing - A Revision of Bloom's Taxonomy of Educational Objectives. Addison Wesley Longman, Inc, 2001.

[2] J. Biggs and C. Tang, Teaching for Quality Learning at University - What the student does, 4th Ed. Maidenhead, England: McGraw-Hill, 2011.

[3] K. Missildine, R. Fountain, L. Summers, and K. Gosselin, "Flipping the classroom to improve student performance and satisfaction," J. Nurs. Educ., vol. 52, no. 10, pp. 597-599, Sep. 2013, doi: 10.3928/01484834-20130919-03.

[4] J. Hattie, Visible learning: A synthesis of over 800 meta-analyses relating to achievement, 1st Ed. London: Routledge, 2008.

[5] C. Hodges, S. Moore, B. Lockee, T. Trust, and A. Bond, "The Difference Between Emergency Remote Teaching and Online Learning," 2020. https://er.educause.edu/articles/2020/3/thedifference-between-emergency-remote-teaching-and-online-learning (accessed March 05, 2021).

[6] A. O. Mohmmed, B. A. Khidhir, A. Nazeer, and V. J. Vijayan, "Emergency remote teaching during Coronavirus pandemic: the current trend and future directive at Middle East College Oman," Innov. Infrastruct. Solut., vol. 5, no. 3, Jul. 2020, doi: 10.1007/s41062-020-00326-7.

[7] C. Rapanta, L. Botturi, P. Goodyear, L. Guàrdia, and M. Koole, "Online University Teaching During and After the Covid-19 Crisis: Refocusing Teacher Presence and Learning Activity," Postdigital Sci. Educ., vol. 2, no. 3, pp. 923-945, Oct. 2020, doi: 10.1007/s42438-020-00155-y.

[8] M. J. Koehler and P. Mishra, "What is Technological Pedagogical Content Knowledge (TPACK)?," Contemp. Issues Technol. Teach. Educ., vol. 9, no. 1, pp. 60-70, 2009, doi: $10.1177 / 002205741319300303$.

[9] G. Orlov et al., "Learning during the COVID-19 pandemic: It is not who you teach, but how you teach," Econ. Lett., vol. 202, p. 109812, May 2021, doi: 10.1016/j.econlet.2021.109812.

[10] P. Jandrić et al., "Teaching in the Age of Covid-19," Postdigital Sci. Educ., vol. 2, no. 3, pp. 10691230, Oct. 2020, doi: 10.1007/s42438-020-00169-6.

[11] D. Popa, A. Repanovici, D. Lupu, M. Norel, and C. Coman, "Using Mixed Methods to Understand Teaching and Learning in COVID 19 Times," Sustainability, vol. 12, no. 20, p. 8726, Oct. 2020, doi: 10.3390/su12208726.

[12] D. Oblinger, "Leading the Transition from Classrooms to Learning Spaces | EDUCAUSE," EDUCASE, pp. 14-18, Jan. 01, 2005.

[13] S. E. Van Nuland, E. Hall, and N. R. Langley, "STEM crisis teaching: Curriculum design with elearning tools," FASEB BioAdvances, vol. 2, no. 11, pp. 631-637, Nov. 2020, doi: 10.1096/fba.202000049.

[14] A. Mutawa, "Synchronous vs. Asynchronous Distance Education During a Worldwide Epidemic," in EDULEARN20 Proceedings, Aug. 2020, vol. 1, pp. 7510-7515, doi: 10.21125/edulearn.2020.1906.

[15] S. Guo, "Synchronous versus asynchronous online teaching of physics during the COVID-19 pandemic," Phys. Educ., vol. 55, no. 6, p. 065007, Nov. 2020, doi: 10.1088/1361-6552/aba1c5. 
[16] M. P. Driscoll, "How People Learn (and What Technology Might Have To Do with It). ERIC Digest," Oct. 2002, Accessed: Mar. 22, 2021. [Online]. Available: www.eric.ed.gov.

[17] J. Hattie, "The Black Box of Tertiary Assessment: An Impending Revolution," in Tertiary Assessment and Higher Education Student Outcomes: Policy, Practice and Research, 1st Ed., L. Meyer, S. Davidson, H. Anderson, R. Fletcher, P. Johnston, and M. Rees, Eds. Ako Aotearoa, 2009, pp. 259276. 